\title{
Finite Element Simulative Analysis of Concrete Arch Dam Structure
}

\author{
Dongyu $\mathrm{Ji}^{1, \mathrm{a}}$, Weixing Chen ${ }^{2, \mathrm{~b}}$
}

${ }^{1}$ Hunan Urban Construction College, Xiangtan, Hunan Province 411101, P.R. China

${ }^{2}$ Survey, Design \& Research Institute of Henan Petroleum Exploration Bureau (HPEB), SINOPEC, Nanyang, Henan Province 473132, P.R. China

ahnjdy@126.com, b1949cwx@163.com

Keywords: Concrete arch dam; Finite element method; Simulation analysis; Stress distribution.

\begin{abstract}
In this paper, finite element simulative analysis is proceeded for the concrete arch dam of Tianshengqiao reservoir. Deducing variation law of the dam's stress and displacement in construction process and operational process. The analytic results are shown: concrete arch dam of Tianshengqiao reservoir is reasonable structure, and every index meets the requirements for design.
\end{abstract}

\section{Introduction}

Tianshengqiao reservoir is located Laliu River, which is located Nandan county in the Guangxi zhuang autonomous region. The main function of reservoir is irrigation, and it is a comprehensive utilization water conservancy and hydropower engineering. The main buildings include concrete arch dam, left bank gravity pier, shore spillway, penstock, power station and underport, etc. Total reservoir storage capacity is 402 million $\mathrm{m}^{3}$, reservoir's normal storage level is $24 \mathrm{~m}$, design level is $28.1 \mathrm{~m}$, flood level is $30.3 \mathrm{~m}$. The dam is concrete single arch dam, maximum dam high is $31.6 \mathrm{~m}$, the arc length of dam crest is $43.44 \mathrm{~m}$, thickness of dam crest is $1.2 \mathrm{~m}$, thickness of dam bottom is $1.7 \mathrm{~m}$, hickness-to-height ratio of arch dam's section is 0.07 . River valley of dam site is ladder-shaped, gravity pier is set at the left bank, river valley is rectangular-shaped.

\section{Calculation Model}

Model Parameters. Concrete strength grade of Tianshengqiao reservoir concrete arch dam is C15, elastic modulus $\mathrm{E}_{1}=22 \mathrm{GPa}^{[1]}$, Poisson ratio $\mu_{1}=0.167$, density $\gamma_{1}=24 \mathrm{kN} / \mathrm{m}^{3}$. The foundation of dam is Qixia limestone of permian period, the limestone is medium thickness seam, lithology is hard, it is basic complete. Rock stratum tends to upstream, karst of dam site is not the development, the rock stratum is not leaking. Rock's elastic modulus $\mathrm{E}_{2}=12 \mathrm{GPa}^{[2]}$, Poisson ratio $\mu_{2}=0.28$.

Model Element. Concrete arch dam and bedrock structure model is divided by eight nodes isoparametric block element. The element is often applied to three-dimensional model of entity structure, it has plasticity, creep, expansion, stress rigidization, large deformation and large strain characteristics. It has eight nodes, each node has three translational degree of freedoms ${ }^{[3]}$.

Model size. Calculation model simulation range is listed below, calculation model along the river is $90 \mathrm{~m}$, transverse of the river is $75 \mathrm{~m}$, vertical direction is $76 \mathrm{~m}$. The simulation range of whole calculation model is $90 \mathrm{~m} \times 75 \mathrm{~m} \times 76 \mathrm{~m}$. Element division of dam and bedrock is shown in Fig.1.

Calculation Cases. Considering mechanical characteristics of dam structure in operating process $^{[4]}$, researching three calculation cases as follows. Case 1, normal storage level and dam weight, case 2, design level, tail water level and dam weight, case 3, flood level, tail water level and dam weight.

\section{Arch Dam Structure Analysis}

Analysis Path. In order to analyzing concrete arch dam of Tianshengqiao reservoir, one analysis path is defined, on the upstream face of crown cantilever, choosing one calculation point every $5 \mathrm{~m}$ 
from dam bottom to dam crest, there are seven calculation points totally, these points assembled analysis path. Stress distribution of the path is provided in the paper.

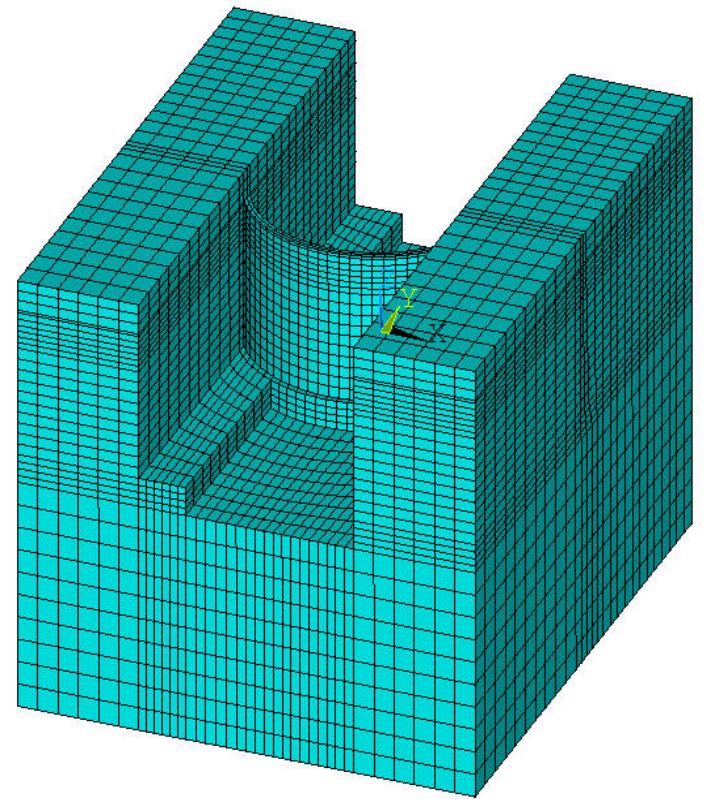

Fig.1 Element division of dam and bedrock

Stress Analysis. In order to researching stress distribution law of crown cantilever, obtaining circumferential and vertical stress values of analysis path under various cases, the stress values of crown cantilever under various cases are listed in the table 1.

Table 1. Calculation point's circumferential and vertical stress values on the dam's analysis path under various cases(MPa)

\begin{tabular}{|c|c|c|c|c|c|c|c|c|}
\hline \multicolumn{2}{|c|}{ Calculation Point } & 1 & 2 & $\mathbf{3}$ & $\mathbf{4}$ & $\mathbf{5}$ & $\mathbf{6}$ & $\mathbf{7}$ \\
\hline \multirow{2}{*}{ Case 1 } & $\begin{array}{c}\text { Circumferential } \\
\text { stress }\end{array}$ & 0.386 & -0.418 & -1.513 & -1.229 & -0.425 & -0.070 & 0.034 \\
\cline { 2 - 9 } & Vertical stress & 1.871 & 0.522 & -0.861 & -0.405 & 0.117 & 0.116 & 0.001 \\
\hline \multirow{2}{*}{ Case 2 } & $\begin{array}{c}\text { Circumferential } \\
\text { stress }\end{array}$ & 0.455 & -0.095 & -1.821 & -1.862 & -1.057 & -0.377 & 0.067 \\
\cline { 2 - 9 } & Vertical stress & 1.850 & 1.089 & -0.981 & -0.583 & -0.092 & 0.056 & 0.001 \\
\hline \multirow{2}{*}{ Case 3 } & $\begin{array}{c}\text { Circumferential } \\
\text { stress }\end{array}$ & 0.559 & -0.513 & -2.219 & -2.226 & -1.452 & -0.736 & -0.137 \\
\cline { 2 - 9 } & Vertical stress & 2.666 & 0.969 & -0.138 & -0.098 & -0.058 & -0.020 & 0.005 \\
\hline
\end{tabular}

We can see from table 1, under various cases, circumferential stress of crown cantilever's upstream face is mainly compressive stress. But vertical stress is mainly tensile stress, tensile stress value is larger especially in the junction of dam bottom and bedrock, this is mainly because the junction appears stress concentration phenomenon. These larger stress values can be reduced by the finite element equivalent stress method ${ }^{[5]}$.

We obtain concrete arch dam's contour maps of first principal stress and circumferential stress under various cases, contour maps are shown from Fig.2 to Fig.7.

We can see from Fig.2, Fig.4 and Fig.6, arch dam's contour map of first principal stress is similar under various cases, maximum principal tensile stress appears the junction of dam bottom and bedrock. And first principal stress values increase with water pressure increases, distribution range of principal tensile stress values also gradually increases. In the Fig.3, Fig.5 and Fig.7, circumferential stress of arch dam is mainly compressive stress, and stress distribution is more complex, near the arch dam's bottom appears tensile stress, but tensile stress values are smaller. 

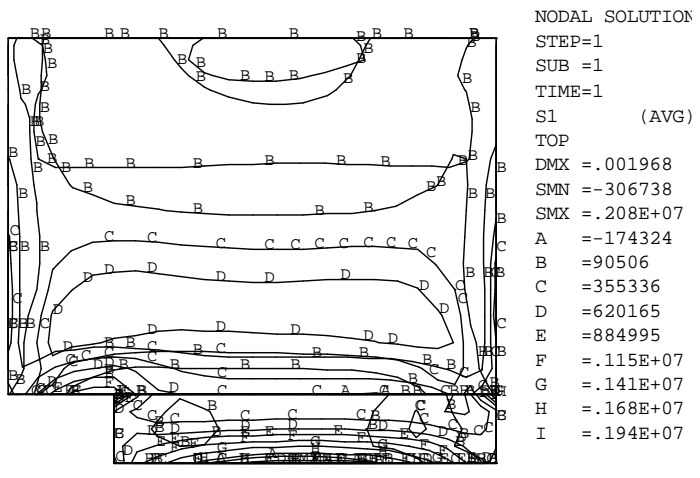

Fig.2 Arch dam's contour map of first principal stress under case $1(\mathrm{~Pa})$

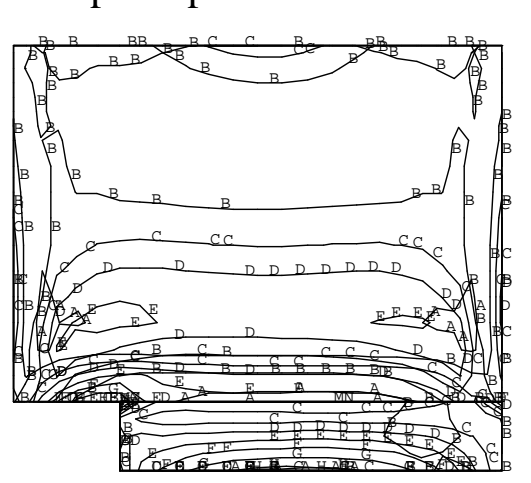

$$
\begin{aligned}
& \text { NODAL SOLUTION } \\
& \text { STEP }=1 \\
& \text { SUB }=1 \\
& \text { TIME }=1 \quad \text { (AVG) } \\
& \text { S1 } \\
& \text { TOP } \\
& \text { DMX }=.002597 \\
& \text { SMN }=-282353 \\
& \text { SMX }=.231 E+07 \\
& \text { A }=-138102 \\
& B \quad=150399 \\
& \text { C }=438901 \\
& D=727402 \\
& \text { E }=.102 E+07 \\
& F=.130 E+07 \\
& G=.159 E+07 \\
& \text { H }=.188 E+07 \\
& \text { I }=.217 E+07
\end{aligned}
$$

Fig.4 Arch dam's contour map of first principal stress under case $2(\mathrm{~Pa})$

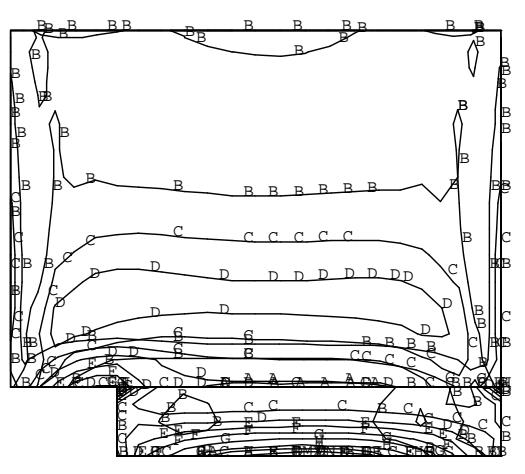

NODAL SOLUTION

STEP $=1$

TIME $=1$

S1

$\mathrm{DMX}=.003232$

SMN $=-402559$

SMX $=.294 \mathrm{E}+07$

A $=-217129$

B $=153729$

$=895446$

$=.127 \mathrm{E}+07$

$=.164 \mathrm{E}+07$

$=.238 \mathrm{E}+07$

$=.275 \mathrm{E}+07$

Fig.6 Arch dam's contour map of first principal stress under case $3(\mathrm{~Pa})$

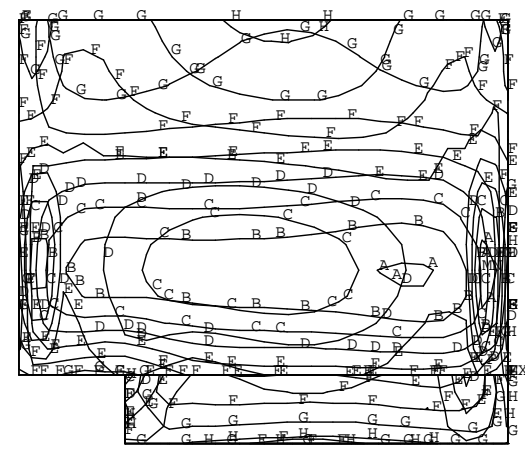

NODAL SOLUTION

STEP $=1$

SUB $=1$

SY

TOP
RSYS $=15$

DMX $=.001968$

SMN $=-.182 E+07$

SMX $=698701$

$=-.168 \mathrm{E}+07$

$=-.112 \mathrm{E}+07$

$=-839361$

$=-559713$

$=-280066$

$=-418.234$
$=279229$

$=558877$

Fig.3 Arch dam's contour map of circumferential stress under case $1(\mathrm{~Pa})$

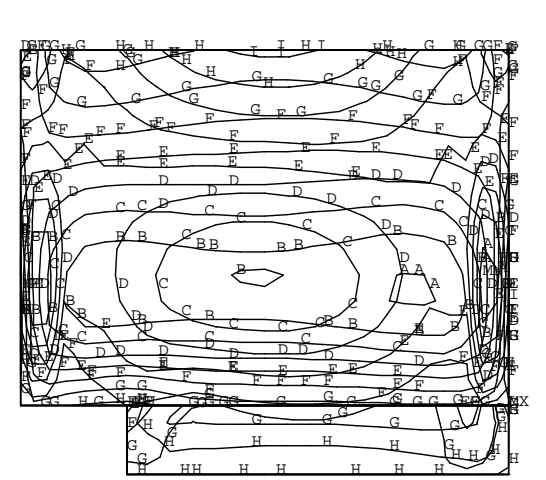

ODAL SOLUTION

Fig.5 Arch dam's contour map of circumferential stress under case $2(\mathrm{~Pa})$

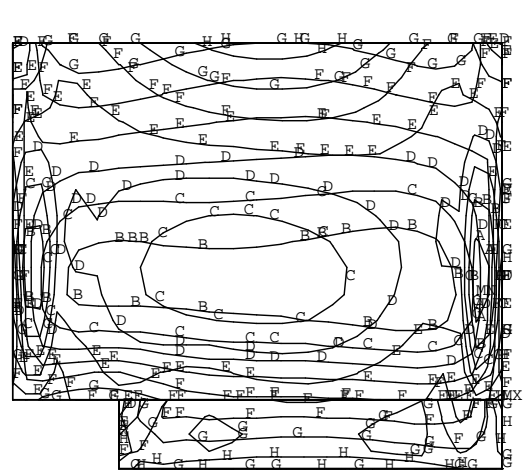

NODAL SOLUTION

STEP $=1$

TIME $=1$

SY

(AVG)

RSYS=15

DMX $=.003232$

SMN $=-.290 \mathrm{E}+07$

SMX $=914744$

$A=-.268 \mathrm{E}+07$

$=-.226 \mathrm{E}+07$

$=-.184 \mathrm{E}+07$

$=-.141 \mathrm{E}+07$

$=-990636$

$=-567218$

$=-143818$

$=703035$

Fig.7 Arch dam's contour map of circumferential stress under case $3(\mathrm{~Pa})$

Displacement Analysis. Through displacement analysis of Tianshengqiao reservoir concrete arch dam, getting radial displacement of crown cantilever's calculation points under various cases, the radial displacement values of crown cantilever under various cases are listed in the table 2, contour maps of displacement under various cases are shown from Fig.8 to Fig.9.

Table 2. Calculation point's radial displacement values on the analysis path of arch dam's crown cantilever under various cases(mm)

\begin{tabular}{|c|c|c|c|c|c|c|c|}
\hline Calculation Point & $\mathbf{1}$ & $\mathbf{2}$ & $\mathbf{3}$ & $\mathbf{4}$ & $\mathbf{5}$ & $\mathbf{6}$ & $\mathbf{7}$ \\
\hline Case 1 & 0.160 & 0.766 & 1.785 & 1.638 & 0.869 & 0.443 & 0.306 \\
\hline Case 2 & 0.057 & 0.579 & 2.177 & 2.446 & 1.734 & 1.049 & 0.640 \\
\hline Case 3 & 0.222 & 1.087 & 2.774 & 3.055 & 2.383 & 1.673 & 1.159 \\
\hline
\end{tabular}



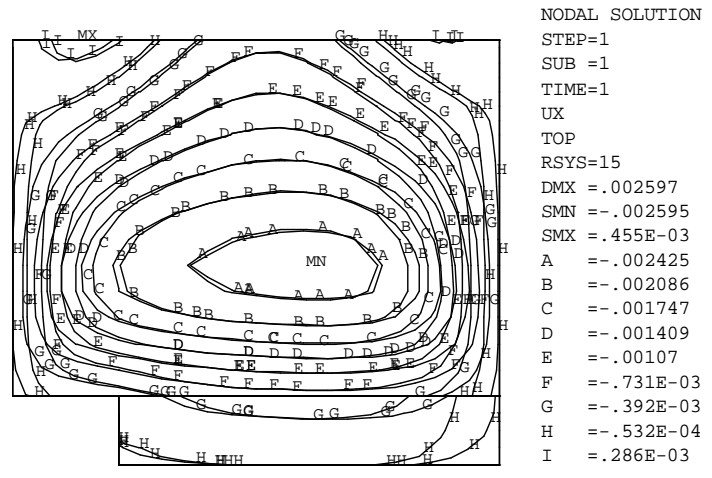

Fig.8 Arch dam's contour map of radial displacement under case 2(Pa)

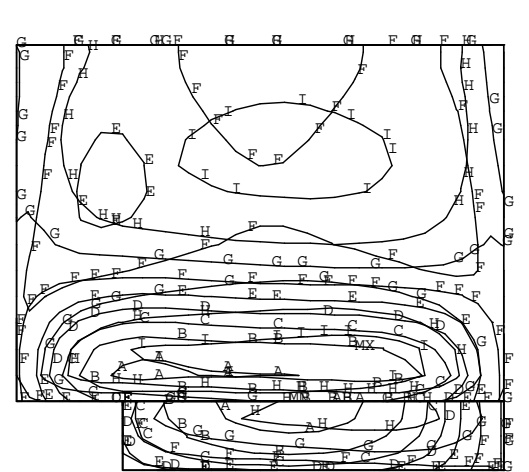

NODAL SOLUTION

$\mathrm{STEP}=1$

TIME $=1$

$\mathrm{UZ}$

RSYS $=15$

DMX $=.002597$

SMN $=-.464 \mathrm{E}-03$ SMX $=.101 \mathrm{E}-03$ $A=-.433 \mathrm{E}-03$ $=-.370 \mathrm{E}-03$ $=-.307 \mathrm{E}-03$ $=-.244 \mathrm{E}-03$ $=-.181 \mathrm{E}-03$ $=-.119 \mathrm{E}-03$ $=-.557 \mathrm{E}-04$ $=.716 \mathrm{E}-05$

Fig.9 Arch dam's contour map of vertical displacement under case 2(Pa)

We can see from table 2, Fig.8 and Fig.9, calculation point's radial displacement values of arch dam's crown cantilever obviously increase with water pressure increases. But maximum radial displacement appears the middle of crown cantilever, displacement values of crown cantilever's top and bottom are smaller. Arch dam's radial displacement values are more larger than vertical displacement values, maximum vertical displacement appears crown cantilever's top.

\section{Conclusion}

From the above, Tianshengqiao reservoir adopts concrete arch dam is economic and reasonable. The arch dam's circumferential stress is basically compressive stress, and arch dam's first principal stress values are smaller, stress values can meet strength requirements, the arch dam structure is safe and reliable.

\section{References}

[1] SL191-2008: Design Code for Hydraulic Concrete Structures(China Water Conservancy and Hydropower Press, China 2008)(in Chinese)

[2] M.R. Shen, J.F. Chen: Rock Mechanics(Tongji University Press, China 2006)(in Chinese)

[3] X.CH. Wang, M. Shao: Finite Element Method Basic Principle and Numerical Method(Tsinghua University Press, China 1997)(in Chinese)

[4] SL282-2003: Design Code for Concrete Arch Dam(China Water Conservancy and Hydropower Press, China 2003)(in Chinese)

[5] B.F. Zhu, J.ZH. Gao, Z.Y. Chen, Y.SH Li: Arch Dam Design and Research(China Water Conservancy and Hydropower Press, China 2002)(in Chinese) 